IZA DP No. 8599

Homeownership and Labour Market Outcomes: Micro versus Macro Performances

Julie Beugnot

Guy Lacroix

Olivier Charlot

October 2014 


\title{
Homeownership and Labour Market Outcomes: Micro versus Macro Performances
}

\author{
Julie Beugnot \\ CRESE, Université de Franche Comté \\ Guy Lacroix \\ Université Laval, CIRPÉE, CIRANO and IZA \\ Olivier Charlot \\ THEMA, Université Cergy-Pontoise
}

Discussion Paper No. 8599

October 2014

\author{
IZA \\ P.O. Box 7240 \\ 53072 Bonn \\ Germany \\ Phone: +49-228-3894-0 \\ Fax: +49-228-3894-180 \\ E-mail: iza@iza.org
}

\begin{abstract}
Any opinions expressed here are those of the author(s) and not those of IZA. Research published in this series may include views on policy, but the institute itself takes no institutional policy positions. The IZA research network is committed to the IZA Guiding Principles of Research Integrity.

The Institute for the Study of Labor (IZA) in Bonn is a local and virtual international research center and a place of communication between science, politics and business. IZA is an independent nonprofit organization supported by Deutsche Post Foundation. The center is associated with the University of Bonn and offers a stimulating research environment through its international network, workshops and conferences, data service, project support, research visits and doctoral program. IZA engages in (i) original and internationally competitive research in all fields of labor economics, (ii) development of policy concepts, and (iii) dissemination of research results and concepts to the interested public.
\end{abstract}

IZA Discussion Papers often represent preliminary work and are circulated to encourage discussion. Citation of such a paper should account for its provisional character. A revised version may be available directly from the author. 
IZA Discussion Paper No. 8599

October 2014

\section{ABSTRACT \\ Homeownership and Labour Market Outcomes: Micro versus Macro Performances}

In this paper we investigate Oswald's hypothesis according to which higher homeownership rates increase aggregate unemployment rates. To this end, we develop a matching model à la Pissarides (2000) in which homeowners are assumed to be less mobile than tenants. Based on numerical simulations, we analyze both macroeconomic and microeconomic labour market outcomes following an (exogenous) increase in homeownership rates. We show that (1) Oswald's hypothesis does not always hold as it depends crucially on the importance of mobility costs; (2) while higher homeownership may harm macroeconomic labour market performances, individual performances always improve following an increase in homeownership rates.

JEL Classification: J41, J61, J64, E24

Keywords: $\quad$ stochastic job matching, Oswald's hypothesis, homeownership, unemployment, mobility

Corresponding author:

Guy Lacroix

Department of Economics

Pavillon J.-A.DeSève

1025, avenue des Sciences humaines

Université Laval

Québec (Québec), G1V OA6

Canada

E-mail: guy.lacroix@ecn.ulaval.ca 


\section{Introduction}

Over the past few decades homeownership rates have increased significantly in many in OECD countries (Andrews and Sánchez, 2011). This increase partly stems from the many programs and policies that have been implemented over the years to foster access to firsttime buyers: subsidized loans, zero interest loans, smaller down payments, tax deductible mortgage interests, etc.

The rationale for subsidizing homeownership is manyfold. Positive externalities in the form of increased health and fertility, lower crime rates, and increased community involvement are often associated with a higher rate of homeownership [see, e.g, Dietz and Haurin (2003) for a summary of the literature]. Yet, another strand of the literature has emphasized its potentially negative effects on the labour market. What is now conventionally referred to as "Oswald's hypothesis" or "Oswald's conjecture" suggests that higher homeownership rates may increase unemployment rates. Variations in homeownership rates are thus potentially important in explaining international and interregional variations in unemployment rates.

Oswald's conjecture stems from a macroeconomic empirical regularity but rests upon microeconomic behavioural assumptions (Oswald, 1996, 1999). The starting point is to reasonably assume that a loan must be contracted to buy a house. This long run financial constraint will very likely affect homeowners' work behaviour relative to tenants', as the latter do not face such a constraint. Second, because the sale or the purchase of a property entails very large transaction costs, owning a house certainly impairs geographic mobility on distant labour markets. The lower mobility of homeowners has been widely confirmed in the empirical literature [Smith et al. (1988) Hammnett (1991), South and Deane (1993), Rohe and Stewart (1996), Henley (1998), Gobillon (2001)]. Lower mobility inhibits search strategies and may translate into poorer match quality, thus giving rise to inefficiencies [Munch et al. (2006), van Vuuren and van Leuvensteijn (2007) ]. In this particular case, lower mobility may translate into homeowners earning lower wage rates. Oswald also argues that homeowners are more willing to commute than tenants over longer distances which also leads to inefficiencies in the economy due to transport congestion.

Several empirical studies have tested Oswald's conjecture using aggregate and microeconomic data [see Havet and Penot (2010) for a detailed survey]. No consensus has yet emerged from the literature. Macroeconomic analyses provide mixed results whereas mi- 
croeconomic studies more clearly refute Oswald's hypothesis. ${ }^{1}$ Empirical studies using microeconomic data mainly focus on the impact of workers' residential status on the probability of being unemployed or on unemployment duration. Most papers show that homeowners have lower probabilities of being unemployed and have shorter spells than tenants on local labour markets. ${ }^{2}$ Interestingly, results are mixed when reemployment requires geographic mobility. Microeconomic studies have also underlined the importance of distinguishing between mortgaged and outright homeowners [Baert et al. (2014)] and the need to account for search behaviour on local and distant labour markets. However, most of these studies are plagued with methodological drawbacks (aggregation bias, endogeneity of residential tenure, etc.) so their conclusions need to be interpreted with caution.

At the theoretical level, microeconomic stylized search models have been developed to investigate Oswald's hypothesis [Oswald (1997); Munch et al. (2006); Dohmen (2005), Coulson and Fisher (2009)]. They all consider an economy within which local and distant labour markets coexist and in which homeowners face mobility costs. In most papers, save Coulson and Fisher (2009), expected wage offers are exogenously drawn from a given distribution or are assumed constant and identical for each worker. Coulson and Fisher (2009), on the other hand, consider wage bargaining and firm entry to take into account the likely effect of homeownership on job creation. Moreover, only Oswald (1997) considers the possibility that homeowners may commute between regions. All find that homeowners are more likely to be unemployed than tenants except Munch et al. (2006) who distinguish between homeowners' performances and reservation wages on local and distant labour markets. Oswald (1997) and Dohmen (2005) find that a higher homeownership rate always leads to a higher aggregate unemployment rate (along with higher wages as in Oswald). Munch et al. (2006) find that the homeownership effect is ambiguous. In their model, Oswald's hypothesis is verified only in the event there are many more job offers on distant labour markets and if there exists a significant gap between tenants and owners' reservation wages. Finally, Coulson and Fisher (2009) show that the correlation between homeownership and

\footnotetext{
${ }^{1}$ Nickell and Layard (1999) and Belot and Van Ours (2001) find a positive and significant impact of homeownership on unemployment rates in several OECD countries. However, when controlling for additional covariates such as lagged unemployment rate, money supply shocks and labour demand, Green and Hendershott (2001) no longer find any significant relationship for 19 OECD countries over the period 19611995. Coulson and Fisher (2009) (U.S.) and Garcia and Hernandez (2004) (Spain) find that an increase in homeownership rate lowers the unemployment rate.

${ }^{2}$ Nearly all empirical studies on the probability of unemployment reject Oswald's arguments, whereas those on unemployment duration generate more controversial results [see Havet and Penot (2010) for details].
} 
aggregate unemployment rates may be non monotonous and that wages vary inversely to unemployment.

Recently, Head and Lloyd-Ellis (2012) have proposed a model in which search frictions in the housing market impact on labour market outcomes. They consider heterogenous locations, endogenous housing construction and endogenous housing prices and rents which then impacts geographic mobility of homeowners and tenants. In their model, homeownership affects labour market outcomes because the price of houses, which reflects their liquidity, affects homeowners geographic mobility. Contrary to previous models, their analysis focuses on the functioning of the housing market and workers' location choices. Search behaviour and search frictions in the labour market are somewhat sidestepped to make the model tractable. When calibrated to match U.S data, it predicts that homeownership has little impact on aggregate unemployment. High homeownership rates, on the other hand, matter more in high unemployment economies.

Most of the literature is thus concerned either with the effects of higher rates of homeownership on aggregate labour market outcomes or, at a microeconomic level, with the impact of housing tenure on individual labour market performances. Our paper distinguishes itself from the previous literature in that we investigate both macroeconomic and microeconomic labour market performances following an (exogenous) increase in homeownership rates, and in that we consider endogenous job creation. Furthermore, as in Head and Lloyd-Ellis (2012), we also allow the housing market to affect the mobility of homeowners, though in a more stylized manner.

Our paper aims at investigating Oswald's conjecture by formalizing the behavioural assumptions of his seminal contributions. To this end, we develop a stochastic job matching model à la Pissarides (2000) in which wage determination results from bargaining between firms and workers. This theoretical apparatus allows to take into account the effect of homeownership on firms' behaviour. Our model is similar in spirit to that of Munch et al. (2006) in that we consider mobility both on local and distant labour markets. As in previous papers, we assume that homeowners are less mobile than tenants on distant labour markets due to mobility costs. The model is parameterized and numerous simulations are conducted. These show that, in the aggregate, tenants always outperform homeowners on the labour market. The simulations also show that the aggregate unemployment rate generally increases when (exogenous) homeownership rates increase, but that housing market efficiency can outdo this to the point of reversing Oswald's conjecture. More importantly, our results indicate that individual performances always improve following an increase in 
homeownership rates. This is because the interactions between the housing and the labour markets are such that both the tenants and the homeowners become less likely to be unemployed, and both end up earning better wages.

The paper is organized as follows. The next section presents the theoretical framework. We underline and motivate the main assumptions of the model. In Section 3 we derive the steady-state equilibrium of the model. In Section 4 we calibrate the model and report the simulation results on numerous outcomes of exogenously increasing the share of homeowners and the the efficiency of the housing market. We conclude the paper in Section 5.

\section{The model}

We propose a theoretical framework à la Pissarides (2000) aimed at evaluating the impact of residential status on individual and aggregate labour market performance. Our focus is on the steady-state equilibrium. Time is continuous and the economy is populated by a continuum of risk-neutral, infinitely-lived agents who share a common discount factor $\rho$. We assume workers and firms to be uniformly distributed along a directed circle whose circumference is normalized to unity. ${ }^{3}$ Firms are identical save for their location on the circle; they are all endowed with a single vacancy, and when a match occurs, the firm produces with a fixed coefficient technology requiring one worker to produce $y+\varepsilon$ units of output. In this setup, y is common to all firms while $\varepsilon$ is match-specific, unknown before the match occurs, and drawn from a stationary distribution $G$ with support $[0 ;+\infty[$, assumed to be common knowledge.

Workers differ in their location on the circle and in their residential status. Residential status matters because finding a job takes time and is costly, and workers may find jobs that are located far from their place of residence. Workers' willingness to accept job offers at different locations depends on mobility costs as well as on expected gains.

\subsection{Residential status and mobility cost}

Workers are constrained in their search by virtue of their residential status which entails different mobility costs. Each worker can either be a homeowner, $h$, or a tenant, $r$. The exogenous share of homeowners is denoted $\mu_{h}=\mu$ and that of tenants by $\mu_{r}=1-\mu$. The economy is represented by the directed circle in Figure 1. Each point on the circle

\footnotetext{
${ }^{3}$ The use of a directed circle makes the model more tractable and allows interpretations in terms of mobility rates.
} 
corresponds to a local labour market. All labour markets are assumed identical so that the situation at a specific point corresponds to the state of the economy.

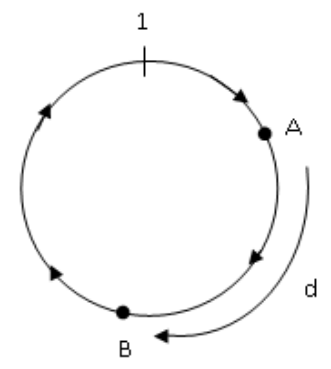

Figure 1: Our economy

As shown in the figure, a worker located at A has to move to accept a job offer at B, i.e. at a distance $d \in[0 ; 1]$. This move entails a cost that differs between homeowners and tenants. For simplicity, we assume that only homeowners bear a mobility cost. Tenants are perfectly mobile and can move freely to any job on the circle. The mobility cost is a function of the state of the housing market, $\lambda$, and the distance, $d$ :

$$
C m(d)=\frac{d}{\lambda}
$$

where $\lambda \in] 0 ; 1]$ is an efficiency index of the housing market. As $\lambda$ nears one the housing market becomes more efficient in that it is easier and less costly for homeowners to sell their house and buy a new one. Thus $\lambda$ proxies both transaction costs (i.e. intermediaries, taxes, etc.) and market liquidity (i.e. the rate at which a dwelling can be transferred between homeowners). When $\lambda=1$, mobility costs boil down to a moving costs that is commensurate to distance. ${ }^{4}$ More generally, we can argue as in Ruppert and Wasmer (2009) that there exists an inverse relationship between regulation and frictions on the housing market. More regulation translates into higher mobility costs and thus housing policies can affect workers' behaviour and overall labour market outcomes.

\footnotetext{
${ }^{4}$ In this case, tenants and homeowners will bear the same mobility cost, $d$. Notwithstanding the latter, we will assume that tenants are perfectly mobile. Assuming otherwise will clutter the model and make it less tractable without changing the qualitative results.
} 


\subsection{Unemployment, vacancies and matching frictions}

A worker can be either employed or unemployed. Only unemployed workers are assumed to search and eventually receive job offers (no on-the-job search). Search is random, and vacant jobs and unemployed workers are brought together in pairs by a customary matching function which relates the number of matches in the market to the total number of job seekers and vacancies, i.e.

$$
M \equiv m(u ; v),
$$

where $u$ and $v$ correspond to the number of job seekers and the number of vacancies, respectively. The function is assumed to be twice continuously differentiable $\left(C^{2}\right)$, increasing and concave in both its arguments, linearly homogeneous, and to satisfy the Inada and the boundary conditions: $m(0 ; v)=m(u ; 0)=0$ for $u, v \geq 0$. On average, a firm contacts a worker at rate $M / u$ while a job seeker meets with a firm at rate $M / v$. Let $\theta=v / u$ be the labour market tightness. Linear homogeneity of the matching function allows us to write the contact rates as $M / v=q(\theta)$ and $M / u=\theta q(\theta)$. Contact rates, $q(\theta)$ and $\theta q(\theta)$, are respectively decreasing and increasing functions of $\theta$. The total number of job seekers in the economy, $u$, consists of unemployed homeowners, $u_{h}$, and unemployed tenants, $u_{r}$ :

$$
u=u_{h}+u_{r}
$$

As unemployed tenants can move without cost, they receive job offers from the whole circle $\left(d_{r}=1\right)$. Thus, they meet vacancies at rate:

$$
\int_{j \in[0,1]} \theta_{j} q\left(\theta_{j}\right) d j=\theta q(\theta)
$$

Unemployed homeowners, on the other hand, bear a mobility cost too high to search and meet job offers located beyond a critical distance $\bar{d} \in[0,1]$. Consequently, they meet vacancies at a lower rate than tenants:

$$
\int_{j \in[0, \bar{d}]} \theta_{j} q\left(\theta_{j}\right) d j=\bar{d} \theta q(\theta) \leq \theta q(\theta)
$$

This critical distance, $\bar{d} \leq 1$, varies according to the mobility cost and corresponds to the distance from which an unemployed homeowner prefers to stay unemployed instead of moving to a new job. 


\subsection{Gains to Firms and Workers}

Value functions are defined as follows. Let $W_{i}$ and $U_{i}$ be the present discounted value (PDV) of the expected income stream of an employed and an unemployed worker with residential status $i=h, r$, respectively. Similarly, let $J_{i}$ be the PDV of the expected profit from filling a job with a worker with residential status $i$, and $V$ the PDV of a vacancy.

\subsubsection{Workers}

The value of being employed, $W_{i}(\varepsilon)$, or unemployed, $U_{i}$, for a type $i=h, r$ worker satisfies

$$
\begin{gathered}
\rho W_{i}(\varepsilon)=w_{i}(\varepsilon)-\delta\left[W_{i}(\varepsilon)-U_{i}\right] . \\
\rho U_{i}=b_{i}+d_{i} \theta q(\theta) \int_{0}^{+\infty} \max \left[W_{i}(\varepsilon)-U_{i}, 0\right] d G(\varepsilon) .
\end{gathered}
$$

A worker $i$ receives a wage, $w_{i}(\varepsilon)$, when employed and has a constant reservation utility $b_{i}$ when unemployed. Job destructions occur at an exogenous Poisson rate $\delta$ in which case a worker incurs a loss equal to $W_{i}(\varepsilon)-U_{i}$. A job seeker receives an offer at rate $d_{i} \theta q(\theta)$, which depends on his residential status. The offer is accepted if it yields a positive expected gain. ${ }^{5}$

While searching, the worker has a reservation utility level, $b_{i}$, that corresponds to unemployment benefits, housing benefits or unpaid leisure activity. This parameter is key to determine which kind of job seekers (e.g. homeowners or tenants) has the largest reservation wage $\rho U_{i}$. Such a reservation wage can vary according to the agents' status on the housing market for several reasons, and opposite effects can be at stake. For instance, mortgage-free homeowners are not eligible to publicly provided housing benefits as opposed to tenants. On the other hand they derive more utility from leisure than mortgaged homeowners as the latter may have to sell their property if the unemployment spell lasts too long. Similarly, homeowners may derive more utility from leisure on the one hand, but may find it more difficult to adjust their housing consumption on the other hand. We thus assume that $b_{h}<b_{r}$, and as a consequence, even in case of perfect mobility $\left(d_{h}=d_{r}=1\right)$, unemployed homeowners have a lower reservation utility than unemployed tenants. This assumption is consistent with Oswald's argument according to which owners are always disadvantaged

\footnotetext{
${ }^{5}$ Recall that $d_{r}=1$ and $d_{h}=\bar{d}<1$.
} 
when unemployed due to their lower ability to adjust their housing consumption.

\subsubsection{Firms}

The PDV of a filled job, $J_{i}(\varepsilon)$, satisfies

$$
\rho J_{i}(\varepsilon)=y+\varepsilon-w_{i}(\varepsilon)-\delta\left[J_{i}(\varepsilon)-V\right] .
$$

A job filled with a worker with residential status $i$ produces $y+\varepsilon$ and yields a wage $w_{i}(\varepsilon)$. The job can be destroyed at an exogenous Poisson rate $\delta$, in which case the firm incurs a loss equal to $J_{i}(\varepsilon)-V$.

The PDV of a vacancy satisfies

$$
\rho V=-c+q(\theta)\left\{\phi \int_{0}^{+\infty} \max \left[J_{h}(\varepsilon)-V, 0\right] d G(\varepsilon)+(1-\phi) \int_{0}^{+\infty} \max \left[J_{r}(\varepsilon)-V, 0\right] d G(\varepsilon)\right\}
$$

where $\phi$ stands for the share of unemployed who are homeowners, and is given by $\phi=\frac{u_{h}}{u_{h}+u_{r}}$. Thus, the value of a vacant job is equal to the expected gain from hiring which occurs at rate $q(\theta)$ minus the cost of keeping the job vacant. As matching is random, the firm can either hire a homeowner or a tenant, so that the gain from hiring is a weighted average, the weights depending on the respective shares of homeowners and tenants in the pool of job seekers.

\subsection{Surpluses and Nash Bargaining}

The surplus of a match between a firm and a worker $i$ with a productivity $\varepsilon, S_{i}(\varepsilon)$, can be written as

$$
S_{i}(\varepsilon)=\left[J_{i}(\varepsilon)-V\right]+\left[W_{i}(\varepsilon)-U_{i}\right] .
$$

It is equal the sum of the net gains to the firm and to the worker $i$ for a given match. In equilibrium, free entry in the for-hire labour market drives rents from vacant jobs to zero, $V=0$. Indeed, firms are assumed to search actively until the expected profit of hiring equals to its cost, i.e. until all rents are exhausted. Consequently, the surplus of a match can be rewritten as

$$
S_{i}(\varepsilon)=J_{i}(\varepsilon)+\left[W_{i}(\varepsilon)-U_{i}\right]
$$


The negotiated wage results from a Nash bargaining between the firm and the worker. The match surplus is shared between them to satisfy the following sharing rule:

$$
W_{i}(\varepsilon)-U_{i}=\frac{\beta}{(1-\beta)} J_{i}(\varepsilon)
$$

where $\beta$ and $(1-\beta)$ represents the bargaining power of workers and firms, respectively.

\subsection{Decision Rules}

The firms and the workers' decision rules determine job acceptance, the reservation productivity on the local labour market as well as the maximum distance homeowners are willing to move.

Not all matches between firms and workers are profitable. Indeed, there exists a common reservation productivity $y+R_{i}$ below which neither the firm nor the worker $i$ wants the match to become effective. In other words, $R_{i}$ represents the match-specific reservation productivity from which the match surplus becomes positive $S_{i}\left(R_{i}\right) \geqslant 0$. Thus, in each local labour market, the reservation productivity $R_{i}$ below which a match is rejected results from

$$
S_{i}\left(R_{i}\right)=0
$$

By analogy to Ruppert and Wasmer (2009), $R_{i}$ also reflects the willingness to commute by each worker. ${ }^{6}$ The smaller $R_{i}$ is, the more a worker is willing to commute to stay in his local labour market.

The critical distance $\bar{d}$ above which homeowners are better off staying unemployed is implicitly defined as:

$$
C_{m}(\bar{d})=\int_{R_{h}}^{+\infty} W_{h}(\varepsilon) d G(\varepsilon)-U_{h} .
$$

\section{Steady State Equilibrium}

The steady-state equilibrium of our economy is given by the 8-tuple $\left(u_{h}^{*}, u_{r}^{*}, \theta^{*}, R_{h}^{*}, R_{r}^{*}\right.$, $\left.w_{h}^{*}(\varepsilon), w_{r}^{*}(\varepsilon), \bar{d}^{*}\right)$ which is solution to the following equations: reservation productivity

\footnotetext{
${ }^{6}$ Indeed, we can consider that $R_{i}$ is inversely related to the largest commuting distance that a worker is willing to undertake.
} 
equations, wage curves, labour market flow equations, job creation curve, critical distance equation. They are defined in this section.

\subsection{Reservation Productivity}

A random match between a firm and a worker becomes effective if and only if the matchspecific productivity is such that $\varepsilon \geqslant R_{i}$, which occurs with a probability $\left[1-G\left(R_{i}\right)\right]$. From the Bellman equations (7), and (6), and equations (10) and (12), we have

$$
R_{i}=\rho U_{i}-y
$$

Thus, the reservation productivity of a match between a firm and a worker $i$ is equal to the difference between the value of being unemployed and the minimum productivity of a match (i.e. when $\varepsilon=0$ ). As unemployed homeowners' utility is lower, they are more willing to accept low productive matches, $R_{h} \leqslant R_{r}$, and longer commute to stay in their local labour market. Moreover, according to equations (10) and (14), and using the reservation rule (12), $S_{i}\left(R_{i}\right)=0$, we have

$$
S_{i}(\varepsilon)=\frac{\varepsilon-R_{i}}{\rho+\delta}
$$

Thus, the lower the unemployed worker's utility is, the larger the surplus of the match. Likewise, the higher the reservation productivity of a worker is, the lower the match surplus. Consequently, we can expect that hiring a homeowner will be more profitable for a firm than employing a tenant.

\subsection{Wages}

Given the free entry condition $V=0$, and equations (6) and (7) and (11), the wages can be written as a weighted average between the workers' outside options, determined by $\rho U_{i}$, and their productivity, $y+\varepsilon$, and are thus given by

$$
w_{i}(\varepsilon)=\beta(y+\varepsilon)+(1-\beta) \rho U_{i}
$$

where $i=h, r$. As $\rho U_{h} \leqslant \rho U_{r}$, equation (16) implies that a homeowner will earn on average a lower wage than a tenant at given productivity.

\subsection{Job Creation Curve}

Given the free entry condition, the surplus sharing rule (11), the reservation productivities $R_{i}$ implied by (14) and the surplus in (15), we can derive from (8) the following job 
creation curve:

$$
\frac{c}{(1-\beta) q(\theta)}=\phi \int_{R_{h}}^{+\infty} S_{h}(\varepsilon) d G(\varepsilon)+(1-\phi) \int_{R_{r}}^{+\infty} S_{r}(\varepsilon) d G(\varepsilon) .
$$

This expression corresponds to a marginal condition of labour demand. Indeed, new jobs are posted until the expected cost of a vacancy equals the expected gain from a filled one. As previously stated, hiring a homeowner will be more profitable for a firm than hiring a tenant. Consequently, we can infer from equation (17) that firms will open more vacancies if homeowners are more numerous in the labour force.

\subsection{Labour Market Flows}

Because only matches with a productivity $\varepsilon \geqslant R_{i}$ become effective, which occurs with a probability $P\left(\varepsilon \geqslant R_{i}\right)=\left[1-G\left(R_{i}\right)\right]$, the exit rates from unemployment are

$$
q_{i}^{w}=d_{i} \theta q(\theta)\left[1-G\left(R_{i}\right)\right]
$$

From these expressions, it turns out that the unemployment hazards depend on labour demand $(\theta)$, on the job seekers' mobility costs $\left(d_{i}\right)$, and on their willingness to commute within a local labour market $\left(R_{i}\right)$. Since $d_{r}=1$, we expect tenants to have a higher unemployment exit rate unless the homeowners' willingness to commute (low $R_{h}$ ) compensates their lack of mobility on the distant labour markets $(\bar{d}<1)$.

In a steady state, unemployment rates are constant. The flow of type $i$-workers $(i=h, r)$ being hired is thus equal to the flow of those who lose their job: ${ }^{7}$

$$
d_{i} \theta q(\theta)\left[1-G\left(R_{i}\right)\right] u_{i}=\delta\left(\mu_{i}-u_{i}\right)
$$

so that

$$
u_{i}=\mu_{i} \frac{\delta}{q_{i}^{w}+\delta}
$$

Thus, workers' unemployment rate is decreasing in the exit rate, $q_{i}^{w}$, and increasing in the job destruction rate, $\delta$.

\footnotetext{
${ }^{7}$ We assume that workers keep their residential status in case they become unemployed or decide to move.
} 


\subsection{Critical Distance}

Equation (13) relates the critical distance $\bar{d}$ to the mobility cost defined by equation (1) and to the worker's expected gain. Using the surplus expression (10) and the sharing rule (11), this writes

$$
\begin{aligned}
& \bar{d}=\lambda\left[\beta \int_{R_{h}}^{+\infty} S_{h}(\varepsilon) d G(\varepsilon)-U_{h} G\left(R_{h}\right)\right] \leqslant 1, \text { or, } \\
& \bar{d}=\lambda\left\{\beta\left[1-G\left(R_{h}\right)\right] E\left[S_{h}(\varepsilon) \mid \varepsilon \geqslant R_{h}\right]-U_{h} G\left(R_{h}\right)\right\} \leqslant 1,
\end{aligned}
$$

where $G\left(R_{h}\right)$ gives the probability that $\varepsilon<R_{h}$. The critical distance above which homeowners will reject all job offers is decreasing in housing market regulation, $\lambda$. Moreover, homeowners will be less willing to move when expected gains from a suitable match are small, independently of labour market frictions.

\section{Numerical Simulations}

In this section, we parameterize our model using common parameter values and conduct a set of simulations to investigate the properties of our economy. ${ }^{8}$ In particular, we highlight the effects of arbitrarily increasing the rate of homeownership and that of housing market efficiency on labour market performances. We analyze the impacts on individual and aggregate performances.

\subsection{Calibration}

For a start, we have to specify the functional forms of the matching function and the match-specific productivity distribution. As in Pissarides (2000), we use a Cobb-Douglas matching function, $m(u ; v)=u^{\eta} v^{1-\eta}$, where $\eta \in[0,1]$ is the matching elasticity with respect to unemployment. In the empirical literature, wage distributions are commonly characterized by a log-normal distribution. We thus assume that the match-specific productivity $\varepsilon$ also follows a lognormal distribution, $\log N(0,1)$, on the interval $] 0,+\infty[$.

We parameterize our model on a monthly basis and the discount rate is appropriately set to 0.996 , which corresponds to a $1.2 \%$ quarterly interest rate. As is common in the literature (see e.g. Petrongolo and Pissarides, 2001), we assume the elasticity of matching function with respect to unemployment, $\eta$, as well as that of worker bargaining power, $\beta$,

\footnotetext{
${ }^{8}$ See the appendix for details about the simulated model.
} 
Table 1: Parameters Values

\begin{tabular}{lcc} 
Parameters & Symbols & Values \\
\hline \hline Discount rate & $\rho$ & 0.996 \\
Matching function elasticity & $\eta$ & 0.5 \\
Workers' bargaining power & $\beta$ & 0.5 \\
Job destruction rate & $\delta$ & 0.034 \\
Minimal productivity of a match & $y$ & 1 \\
Vacancy cost & $c$ & 0.6 \\
Homeowners' reservation utility & $b_{h}$ & 0.9 \\
Tenants' reservation utility & $b_{r}$ & 1.5 \\
\hline
\end{tabular}

to be equal to 0.5 . The exogenous job destruction rate is set to $\delta=0.034$, which roughly corresponds to an average job life of 2.5 years. We normalize the minimal productivity of a match, $y$, to one. The vacancy cost, $c$, is set to 0.6 , which more or less corresponds to $25 \%$ of the average productivity of a match in our economy. ${ }^{9}$ We choose reservation utilities of homeowners and tenants so that $b_{h}$ is equal to $60 \%$ of $b_{r}$ and choose the value $b_{h}=0.9$ and $b_{r}=1.5$. Consequently, even if homeowners were assumed to be perfectly mobile, their permanent income when unemployed would still be lower. ${ }^{10}$

We solve the model over a grid in the $\mu \in] 0 ; 100 \%[\times \lambda \in[0.5 ; 1]$ space in order to gauge both the effects of homeownership rates and housing market efficiency on labour market outcomes.

\subsection{Main steady-state effects}

It can be shown that arbitrarily changing the proportion of homeowners will have three broad effects: a composition effect, an entry effect and a competition effect. ${ }^{11}$ The relative strength of each will determine the net impact on labour market outcomes of homeownership rates . A change in the efficiency of the housing market, on the other hand, will be limited

\footnotetext{
${ }^{9}$ Given the distribution of $\varepsilon$ and the normalization of $y$, the average productivity of a match is given by $y+E(\varepsilon \mid \varepsilon>0) \simeq 2.65$. Note that higher or lower values of $c$ will not affect the qualitative results of our model.

${ }^{10}$ Note that the levels of $b_{h}$ and $b_{r}$ have no influence on the qualitative results, only the gap between them matters.

${ }^{11}$ The first two are identical to those in Coulson and Fisher (2009).
} 
to the competition effect. Before we dwell into the simulation results, we discuss each effect in turn as they are key in understanding our results.

1. Composition effect: Increasing the share of homeowners in the economy will have a purely mechanical impact on aggregate performances. Indeed, if homeowners have better (worse) labour market performances than tenants, increasing their share will improve (worsen) aggregate labour market performances.

2. Entry effect: Hiring a homeowner is usually more profitable for a firm since the resulting surplus is higher for a given match-specific productivity level (see equation (10)). Therefore, arbitrarily increasing the share of homeowners in our economy will increase firms' expected profit. This will induce new firms to enter the market and post new vacancies (see equation (17)). As a result, the labour market becomes tighter and firms' contact rates decrease. Conversely, workers' contact rates increase and the average duration of unemployment decreases. At the aggregate level, the unemployment rate and the average wage rate should improve. The increased competition between firms reduces homeowners' mobility because of the new job opportunities in local labour markets.

3. Competition effect: This effect refers to the competition between unemployed workers on local and distant labour markets. As homeowners are imperfectly mobile on distant labour markets due to mobility costs, increasing their share in the labour force will reduce the number of outside job seekers (because perfectly mobile workers are proportionately fewer) in each local labour market. Consequently, the competition between unemployed workers will be weaker on each local labour market. An increase in the housing market efficiency, on the other hand, will have the opposite effect: by enhancing their mobility, homeowners will seek jobs in more distant labour markets. This increases their job opportunities and strengthens the competition between unemployed owners and tenants on distant labour markets at the expense of tenants.

Clearly, the relative labour market outcomes of two economies who only differ in terms of their relative share of homeowners will depend on the relative strength of the above effects and on their relative mobility costs. The following simulations aim at illustrating the likely labour market equilibrium outcomes of such economies. 


\subsection{Individual Labour Market Performances}

As mentioned earlier, we solve the model repeatedly for different combinations of homeownership rates and mobility costs defined over the grid $\mu \in] 0 ; 100 \%[\times \lambda \in[0.5 ; 1]$. Figures 2 to 6 report the results of our simulations. The three-dimensional figures depict the range of homeownership rates and housing market efficiency on the horizontal axes. The vertical axis reports the equilibrium variable of interest. Each dot in a figure corresponds to a specific $\mu-\lambda$ combination.

Figure 2 focuses on the equilibrium unemployment rates of homeowners and tenants as we vary the two exogenous variables. Figure 2(a) shows that the unemployment rates of homeowners decrease when their share in the economy increases and, not surprisingly, when their mobility cost decreases. Tenants also benefit from having proportionately more homeowners in the economy, as shown in Figure 2(b). This is a direct consequence of the entry effect. The figure also illustrates the competition effect on distant labour markets as their equilibrium unemployment rates increase when homeowners are more mobile.

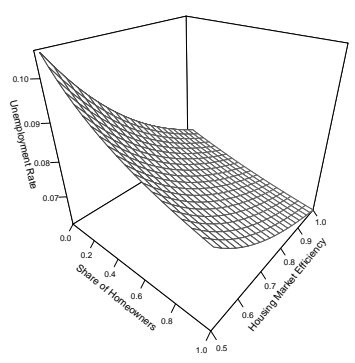

(a) Homeowners

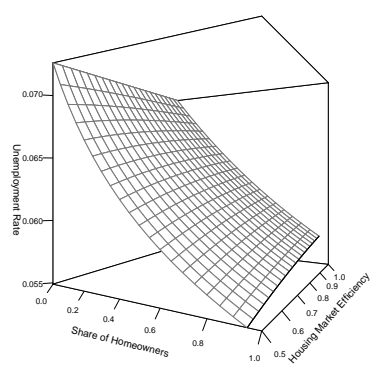

(b) Renters

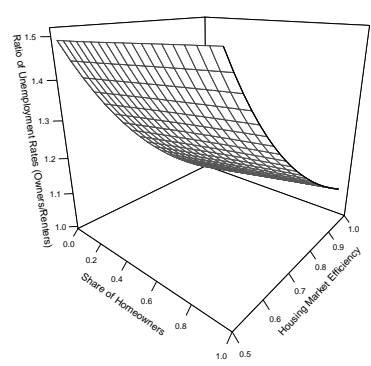

(c) Ratio

Figure 2: Unemployment Rate

While both homeowners and tenants are better off in an economy where the former are proportionately more numerous, tenants are generally better off than homeowners. Indeed, Figure 2(c) shows that difference between their relative unemployment rates increases as the share of homeowners increases. In other words, the unemployment rate of tenants decreases more rapidly as the share of homeowners increases. This comes from the competition effect on local labour markets which is higher for tenants. Indeed, when homeownership rate increases, the number of outside job seekers decreases in each local labour market (because they are less mobile). Consequently, as tenants search in all local labour markets, they 
benefit much more from the reduced competition.

Figure 3 focuses on average wage rates. It shows that homeowners (Figure 3(a)) and tenants (Figure 3(b)) enjoy better wage rates as the proportion of homeowners increases. Once again, this is a direct consequence of the entry effect. Nevertheless, Figure 3(c) also shows tenants benefit more than homeowners do (because of the competition effect on local labour markets). As expected, increased mobility is more beneficial to homeowners (because of the competition effect on distant labour markets).

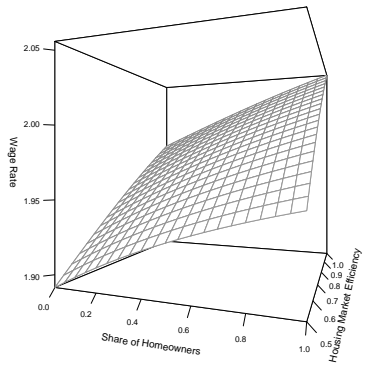

(a) Homeowners

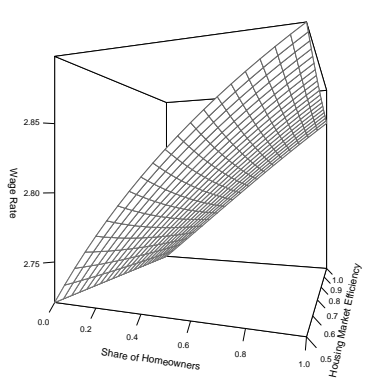

(b) Renters

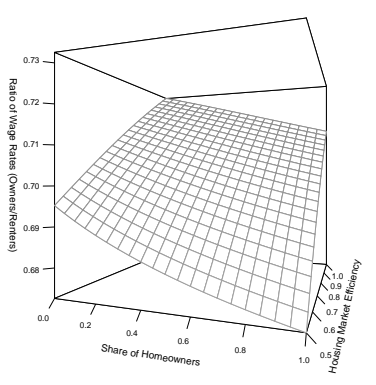

(c) Ratio

Figure 3: Average Wage

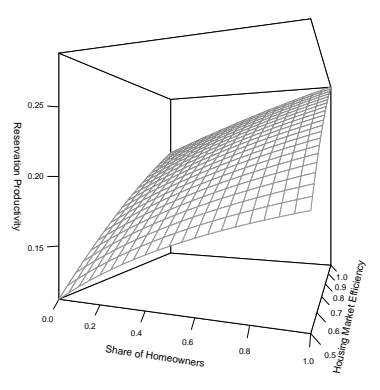

(a) Homeowners

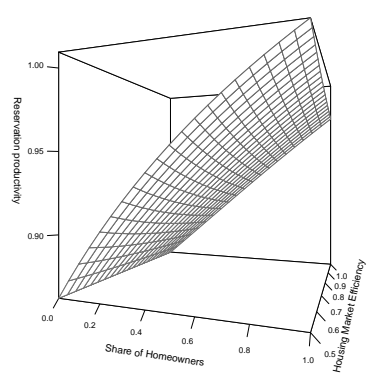

(b) Renters

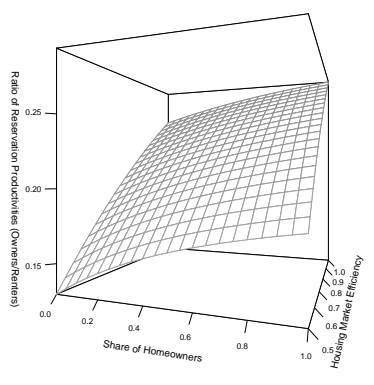

(c) Ratio

Figure 4: Reservation Productivity

Much the same applies to exit rates from unemployment (Figure 5): Increased shares of homeowners is beneficial to everyone, but more so for tenants. Finally, Figure 4 is consistent with the fact that homeowners accept less productive jobs or commute more than tenants 
to stay in their local labour market (see equation (14)): Their reservation productivity is everywhere lower. Thus, although they are more mobile within the local labour market, homeowners are less likely to exit unemployment due to their lack of mobility on distant labour markets (See figure 5(c)).

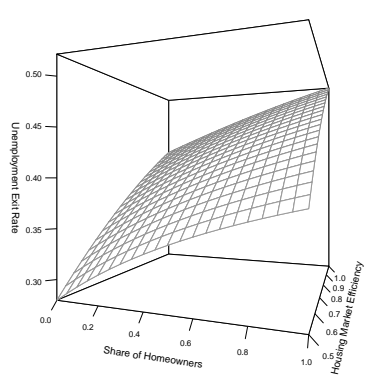

(a) Homeowners

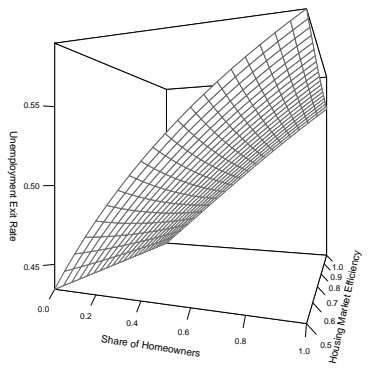

(b) Renters

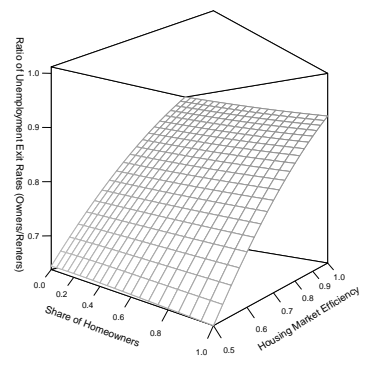

(c) Ratio

Figure 5: Unemployment Exit Rate

Our simulations indicate that higher homeownership rates have performance enhancing effects at the individual level. Indeed, both homeowners and tenants are less out of work, earn higher wages and exit unemployment more easily. These positive effects result from both the entry effect and the competition effect on local labour markets. We are also led to conclude that higher rates of homeownership is more beneficial to tenants. This stems from the competition effect in that tenants face less outside competition on each local labour market. Finally, the simulations show that, not surprisingly, enhanced housing market efficiency only benefits homeowners (competition effect on distant labour markets).

\subsection{Aggregate Labour Market Performances}

We now turn to the effects of homeownership rates and housing market efficiency on aggregate performances. The previous section has shown that homeowners and tenants are usually better off in an economy with proportionately more homeowners. But it has also shown that tenants usually outperform homeowners on the labour market. Two questions thus need to be addressed: First, is it always the case that increasing the share of (lowerperforming) homeowners necessarily leads to worse aggregate performances, in particular to higher aggregate unemployment rates as conjectured by Oswald? Second, does the latter always hold irrespective of the efficiency of the housing market? The previous section has 
focused exclusively on the entry and competition effects. Here we consider the composition effect in addition to the latter two.

\subsubsection{Homeownership Rates and Aggregate Unemployment Rates}

Figure 6(c) depicts the steady-state relationship between homeownership rates and aggregate unemployment rates. Our model yields a positive relationship as conjectured by Oswald when mobility is costly (low values of $\lambda$ ). However, as the housing market becomes more efficient, the relation flattens out and eventually becomes negative. ${ }^{12}$ The non-monotonicity stems directly from mobility costs. Indeed, when homeowners are little mobile, the composition effect outweighs the entry and the competition effects. Conversely, when the housing market becomes more efficient, the difference between the labour market performances of homeowners and tenants decreases significantly due to enhanced competition between them on distant labour markets. Thus, for a large enough $\lambda$ the positive entry and competition effects more than compensate the negative composition effect.

Figure 6(c) also shows that the unemployment rate decreases rapidly with $\lambda$, the efficiency of the housing market, and more so when the homeownership rate is high. Indeed, when $\lambda$ increases homeowners behave more and more like tenants which enhances competition on distant labour markets. This increased competition benefits homeowners at the expense of tenants.

\subsubsection{Homeownership Rates and Labour Markets Performances}

Figure 6(a) investigates the relation between the aggregate average wage rate and homeownership rates. Recall from Section 3.2 that homeowners are predicted to have a lower wage on average. Not surprisingly then, the figure shows that the average aggregate wage rate declines rapidly with the homeownership rate. In our set-up, the composition effect always dominates the entry and the competition effects on local labour markets. On the other hand, a more efficient housing market will increase homeowners' wages more than it will decrease tenants' wage rates (see Figure 3(c)). Consequently, the aggregate average wage rate will increase as the housing market is made more efficient.

Finally, we report the critical distance in Figure 6(b). This corresponds to the share of homeowners who are willing to move to a distant labour market to accept a job. The figure

\footnotetext{
${ }^{12}$ This occurs for values of $\lambda$ above 0.8 in our numerical setting. Note that for $\lambda=0.8$, owners are half as mobile as tenants on distant labour markets.
} 


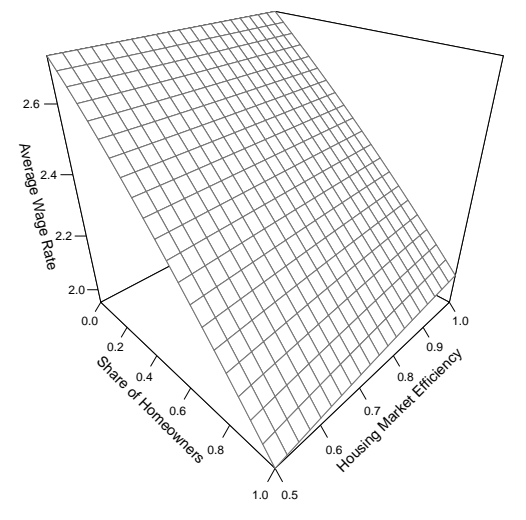

(a) Average Wage

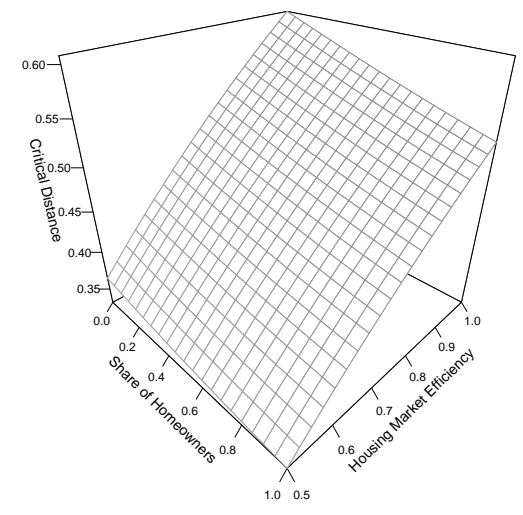

(b) Critical Distance

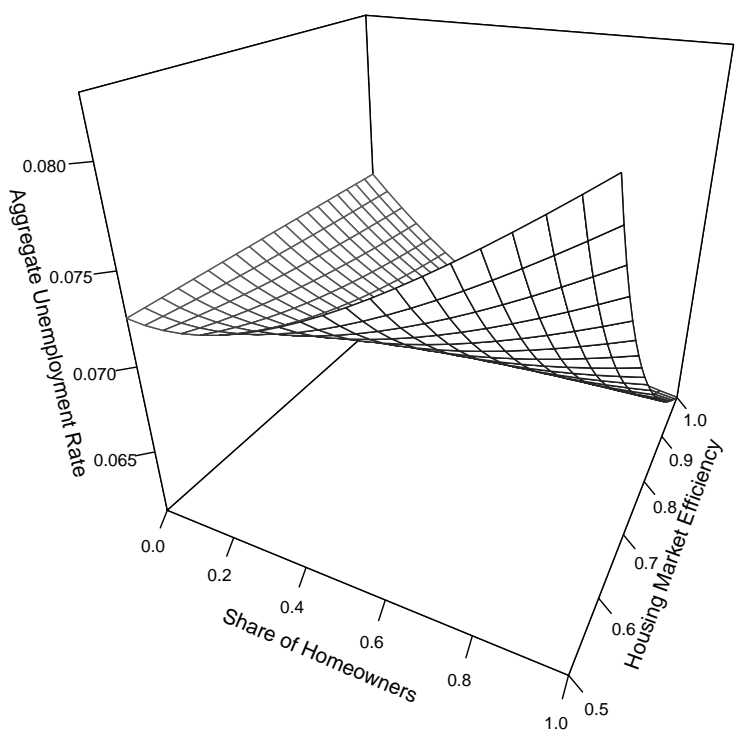

(c) Unemployment Rate

Figure 6: Aggregate Performances 
shows that irrespective of $\lambda$, fewer are willing to move when homeownership rates increase. This stems from the fact that homeowners face less competition from distant job seekers as there are fewer tenants in the economy ( competition effect on local labour markets). In addition, more numerous homeowners will foster additional opportunities on local labour markets (enhanced entry effect).

\section{Conclusion}

In this paper, we examine the effect of homeownership on labour market performances according to the conditions on the housing market which influence mobility costs. Our results show that even if the correlation between homeownership and aggregate performances may be negative, individuals are always better off in an economy in which homeownership is promoted. Furthermore, we show that Oswald's conjecture about aggregate unemployment may be invalid if competition on distant labour markets between homeowners and tenants is strong enough. In our economy, such a competition level can be achieved with low enough mobility costs. Thus, the main problem does not seem to be homeownership per se, but the homeowners' low mobility that arises due to high transaction costs. Thus our findings suggest that policies that foster homeownership should be accompanied by a deregulation of the housing market, thereby lowering mobility costs are reaping the benefits associated with higher rates of homeowners.

We reckon that the choice of residential status is exogenous in our economy. In addition, the housing market is introduced so as to impose mobility costs. Future work should attempt to enlarge housing market effects by endogenizing the tenure choices of workers. 


\section{References}

[1] Andrews, D. and A.C. Sánchez, "The Evolution of Homeownership Rates in Selected OECD Countries: Demographic and Public Policy Influences", OECD Journal: Economic Studies, Volume 2011/1, 207-243.

[2] Baert, S., F. Heylen and D. Isebaert (2014), "Does homeownership lead to longer unemployment spells? The role of mortgage payments", De Economist 162, 263-286

[3] Belot, M. and J. van Ours (2001), "Unemployment and labor market institutions: An empirical analysis", Journal of the Japanese and International Economies 15(4), 403-418

[4] Coulson, E. and L. Fisher (2009), "Housing tenure and labor market impacts: The search goes on",Journal of Urban Economics 65(3), 252-264

[5] Dietz, D.D. and R.D. (2003), "The social and private micro-level consequences of homeownership", Journal of Urban Economics 54(3), 401-450

[6] Dohmen, T.J. (2005), "Housing, mobility and unemployment", Regional Science and Urban economics 35, 305-325

[7] Garcia, J. and J. Hernandez (2004), "User cost changes, unemployment and homeownership: Evidence from Spain", Urban Studies 41(3), 563-578

[8] Gobillon, L. (2001) "Emploi, logement et mobilité résidentielle", Economie et Statistique $349-350(9 / 10), 77-98$

[9] Green, R. and P. Hendershott (2001), "Home-ownership and unemployment in the US", Urban Studies 38(9), 1509-1520

[10] Hammnett, C. (1991), "The relationship between residential migration and housing tenure in London, 1971-81: a longitudinal analysis.", Environment and Planning A 23(8), 1147-1162

[11] Havet, N. and A. Penot (2010), "Does homeownership harm labour market performances? A survey", Working Papers 1012, Groupe d'Analyse et de Théorie Economique (GATE) 
[12] Head, A. and H. Lloyd-Ellis (2012), "Housing Liquidity, Mobility and the Labour Market", forthcoming in Review of Economic Studies, 1-31

[13] Henley, A. (1998), "Residential mobility, housing equity and the labour market.", The Economic Journal 108(447), 414-427

[14] Munch, J-R., M. Rosholm, and M. Svarer (2006), "Are home owners really more unemployed ?", The Economic Journal 116(514), 991-1013

[15] Nickell, S, and R Layard (1999), "Labor market institutions and economic performance", In Handbook of Labour Economics, ed. Orley Ashenfelter and David Card, vol. 3 pp. 3029-3084

[16] Oswald, A. (1996), "A conjecture on the explanation for high unemployment in the industrialised nations: part 1", University of Warwick Economic Research Papers

[17] Oswald, A. (1997), "Theory of homes and jobs", Working paper, University of Warwick

[18] Oswald, A (1999), "The housing market and Europe's unemployment: A non technical paper", Working paper, University of Warwick

[19] Petrongolo, B. and C.A. Pissarides (2001), "Looking into the Black Box: A Survey of the Matching Function", Journal of Economic Literature, 39(2), 390-431

[20] Pissarides, C.A. (2000), Equilibrium unemployment theory, Second Edition, The MIT Press, Cambridge

[21] Rohe, W. and L. Stewart (1996), "Homeownership and neighborhood stability.", Housing Policy Debate 7(1), 173-184

[22] Rupert, P. and E. Wasmer (2009), "Housing and the Labor Market: Time to Move and Aggregate Unemployment", IZA Discussion Paper N4172, May

[23] Smith, L. K. Rosen and G. Fallis (1988), "Recent developments in economic models of housing markets", Journal of Economic Literature 26, 29-64

[24] South, S.J., and G.D. Deane (1993), "Race and mobility: individualtenant determinants and structural constraints", Social Forces 72(1), 147-167

[25] van Vuuren, A., and M. van Leuvensteijn (2007), "The impact of homeownership on unemployment in the Netherlands", CPB Discussion Paper 86, 53 


\section{Appendix}

\section{Appendix A: Simulated equilibrium equations}

At the steady state, the equilibrium of our economy is determined by a system of 8 equations (equations $1 \mathrm{~A}$ to $8 \mathrm{~A}$ ) with 8 unknowns $\left(u_{h}, u_{r}, \theta, R_{h}, R_{r}, \bar{w}_{h}, \bar{w}_{r}, \bar{d}\right)$.

We assume a $\log$ normal distribution for $\varepsilon$ defined on the interval $[0,+\infty$ [ with $G(\varepsilon)$ the cumulative density function and $g(\varepsilon)=\frac{d G(\varepsilon)}{d \varepsilon}$ the density function. Due to numerical convergence concerns, we truncate the distribution at a superior born $\varepsilon_{\max }$ large enough so that we have $G\left(\varepsilon_{\max }\right) \rightarrow 1$. As a consequence, we have: ${ }^{13}$

$P\left(\varepsilon_{\max } \geqslant \varepsilon \geqslant R_{h}\right)=\int_{R_{i}}^{\varepsilon_{\max }} \frac{g(\varepsilon) d \varepsilon}{G\left(\varepsilon_{\max }\right)}=\frac{G\left(\varepsilon_{\max }\right)-G\left(R_{i}\right)}{G\left(\varepsilon_{\max }\right)}=1-G\left(R_{i}\right) / G\left(\varepsilon_{\max }\right) \rightarrow 1-G\left(R_{i}\right)$

In what follows, the simulated model is presented given that exogenous truncation.

The flows equations of unemployment rates are:

$$
\begin{gathered}
u_{h}=\mu \frac{\delta}{\bar{d} \theta q(\theta)\left[1-G\left(R_{h}\right) / G\left(\varepsilon_{\max }\right)\right]+\delta} \\
u_{r}=(1-\mu) \frac{\delta}{\theta q(\theta)\left[1-G\left(R_{r}\right) / G\left(\varepsilon_{\max }\right)\right]+\delta}
\end{gathered}
$$

where $\theta q(\theta)=\theta^{1-\eta}$.

The reservation productivity of homeowners is given by:

$$
R_{h}=\rho U_{h}-y=b-y+\beta \frac{\bar{d} \theta q(\theta)}{\rho+\delta} \int_{R_{h}}^{\varepsilon_{\max }}\left(\varepsilon-R_{h}\right) \frac{d G(\varepsilon)}{G\left(\varepsilon_{\max }\right)}
$$

and following an integration by parts we have:

$$
R_{h}=b_{h}-y+\beta \frac{\bar{d} \theta q(\theta)}{\rho+\delta}\left[\left(\varepsilon_{\max }-R_{h}\right)-\int_{R_{h}}^{\varepsilon_{\max }} \frac{G(\varepsilon) d \varepsilon}{G\left(\varepsilon_{\max }\right)}\right]
$$

In the same way, we have for the following reservation productivity of tenants:

\footnotetext{
${ }^{13}$ When the inferior born is endogenously determined by our model. In the contrary, we have:

$$
\int_{R_{i, t}}^{\varepsilon_{\max }} g(\varepsilon) d \varepsilon=\frac{G\left(\varepsilon_{\max }\right)-G\left(R_{i, t}\right)}{G\left(\varepsilon_{\max }\right)-G\left(R_{i, t}\right)}=1
$$
}




$$
\begin{aligned}
& R_{r}=\rho U_{r}-y=b-y+\beta \frac{\theta q(\theta)}{\rho+\delta} \int_{R_{r}}^{\varepsilon_{\max }}\left(\varepsilon-R_{r}\right) \frac{d G(\varepsilon)}{G\left(\varepsilon_{\max }\right)} \\
& R_{r}=b_{r}-y+\beta \frac{\theta q(\theta)}{\rho+\delta}\left[\left(\varepsilon_{\max }-R_{r}\right)-\int_{R_{r}}^{\varepsilon_{\max }} \frac{G(\varepsilon) d \varepsilon}{G\left(\varepsilon_{\max }\right)}\right]
\end{aligned}
$$

According to the expressions of surplus, the job creation curve is given by:

$$
\begin{aligned}
& \frac{c(\rho+\delta)}{(1-\beta) q(\theta)}=\phi \int_{R_{h}}^{\varepsilon_{\max }}\left(\varepsilon-R_{h}\right) d G(\varepsilon)+(1-\phi) \int_{R_{r}}^{\varepsilon_{\max }}\left(\varepsilon-R_{r}\right) d G(\varepsilon) \\
& \frac{c(\rho+\delta)}{(1-\beta) q(\theta)}=\phi_{t}\left[\left(\varepsilon_{\max }-R_{h}\right)-\int_{R_{h}}^{\varepsilon_{\max }} \frac{G(\varepsilon) d \varepsilon}{G\left(\varepsilon_{\max }\right)}\right]+\left(1-\phi_{t}\right)\left[\left(\varepsilon_{\max }-R_{r}\right)-\int_{R_{r}}^{\varepsilon_{\max }} \frac{G(\varepsilon) d \varepsilon}{G\left(\varepsilon_{\max }\right)}\right]
\end{aligned}
$$

where $q(\theta)=A \theta^{-\eta}, \phi=\frac{u_{h}}{u_{h}+u_{r}}, 1-\phi_{t}=\frac{u_{r}}{u_{h}+u_{r}}$

The average wage of homeowners $\bar{w}_{h}$ is given by:

$$
\begin{aligned}
E\left[w_{h}(\varepsilon) \mid \varepsilon_{\max } \geqslant \varepsilon \geqslant R_{h}\right] & =\int_{R_{h}}^{\varepsilon_{\max }} w_{h}(\varepsilon) \frac{d G(\varepsilon)}{G\left(\varepsilon_{\max }\right)-G\left(R_{h}\right)} \\
& =\int_{R_{h}}^{\varepsilon_{\max }}\left[\beta(y+\varepsilon)+(1-\beta) \rho U_{h}\right] \frac{d G(\varepsilon)}{G\left(\varepsilon_{\max }\right)-G\left(R_{h}\right)}
\end{aligned}
$$

which gives after an integration by parts:

$$
E\left[w_{h}(\varepsilon) \mid \varepsilon_{\max } \geqslant \varepsilon \geqslant R_{h}\right]=\beta y+(1-\beta) \rho U_{h}+\beta\left[\frac{\varepsilon_{\max } G\left(\varepsilon_{\max }\right)-R_{h} G\left(R_{h}\right)-\int_{R_{h}}^{\varepsilon_{\max }} G(\varepsilon) d \varepsilon}{G\left(\varepsilon_{\max }\right)-G\left(R_{h}\right)}\right]
$$

In the same way, the average wage of tenants $\bar{w}_{r}$ is given by:

$$
\begin{aligned}
E\left[w_{r}(\varepsilon) \mid \varepsilon_{\max } \geqslant \varepsilon \geqslant R_{r}\right] & =\int_{R_{r}}^{\varepsilon_{\max }} w_{r}(\varepsilon) \frac{d G(\varepsilon)}{G\left(\varepsilon_{\max }\right)-G\left(R_{r}\right)} \\
& =\beta y+(1-\beta) \rho U_{r}+\beta\left[\frac{\varepsilon_{\max } G\left(\varepsilon_{\max }\right)-R_{r} G\left(R_{r}\right)-\int_{R_{r}}^{\varepsilon_{\max }} G(\varepsilon) d \varepsilon}{G\left(\varepsilon_{\max }\right)-G\left(R_{r}\right)}\right]
\end{aligned}
$$


with

$$
\begin{aligned}
& \rho U_{h}=b_{h}+\beta \frac{\bar{d} \theta q(\theta)}{\rho+\delta}\left[\left(\varepsilon_{\max }-R_{h, t}\right)-\int_{R_{h}}^{\varepsilon_{\max }} \frac{G(\varepsilon) d \varepsilon}{G\left(\varepsilon_{\max }\right)}\right] \\
& \rho U_{r}=b_{r}+\beta \frac{\theta q(\theta)}{\rho+\delta}\left[\left(\varepsilon_{\max }-R_{r}\right)-\int_{R_{r}}^{\varepsilon_{\max }} \frac{G(\varepsilon) d \varepsilon}{G\left(\varepsilon_{\max }\right)}\right]
\end{aligned}
$$

Critical distance:

$$
\begin{aligned}
\bar{d} & =\lambda\left\{\frac{\beta}{\rho+\delta} \int_{R_{h}}^{\varepsilon_{\max }}\left(\varepsilon-R_{h}\right) \frac{d G(\varepsilon)}{G\left(\varepsilon_{\max }\right)}-G\left(R_{h}\right) U_{h}\right\} \\
& =\lambda\left\{\frac{\beta}{\rho+\delta}\left[\left(\varepsilon_{\max }-R_{h}\right)-\int_{R_{h}}^{\varepsilon_{\max }} \frac{G(\varepsilon) d \varepsilon}{G\left(\varepsilon_{\max }\right)}\right]-G\left(R_{h}\right) U_{h}\right\}
\end{aligned}
$$

